\title{
Ближневосточная политика Франции в период президентства Николя Саркози и Франсуа Олланда
}

\author{
М.А. Ивашкин \\ Национальный исследовательский Нижегородский государственный университет \\ им. Н.И. Лобачевского, \\ Россия, 603950, г. Нижний Новгород, пр. Гагарина, 23 \\ E-mail: mikhail.ivashkin@gmail.com
}

\begin{abstract}
Аннотация. Статья посвящена анализу взаимоотношений Франции с государствами ближневосточного региона через призму внешнеполитического курса Николя Саркози и Франсуа Олланда. Ближневосточное направление внешней политики является традиционным для республики, в связи с чем входит в сферу внешнеполитических приоритетов лидеров государства. Цель данной работы заключается в сравнении ближневосточной политики Франции при президентстве Н. Саркози с курсом Ф. Олланда. Для достижения обозначенной цели требуется решить ряд задач: исследовать реализацию внешнеполитического курса президентов в отношении стран Ближнего Востока; выделить общие тенденции ближневосточной политики двух президентов; проанализировать различия между их ближневосточной политикой. В конечном итоге автор приходит к выводу о преемственности взглядов президентов в 2007-2014 гг., сохранением большинства традиционных контактов и расширением сотрудничества. Изменения заключаются в интенсивности взаимодействия. Так, личные качества и убеждения обоих политиков укрепили одни связи и вызвали охлаждение других, вызвали перестановку некоторых акцентов.
\end{abstract}

Ключевые слова: Франция, Ближний Восток, Николя Саркози, Франсуа Олланд, Ливия, Сирия, Ирак, ОАЭ, Саудовская Аравия, внешняя политика.

Для цитирования: Ивашкин М.А. 2020. Ближневосточная политика Франции в период президентства Николя Саркози и Франсуа Олланда. Via in tempore. История. Политология, 47 (4): 912-920. DOI: 10.18413/2687-0967-2020-47-4-912-920.

\section{French middle eastern policy during the presidency of Nicolas Sarkozy and Francois Hollande}

\author{
Mikhail A. Ivashkin \\ National Research Lobachevsky State University of Nizhnii Novgorod, \\ 23 Gagarin Ave., Niznii Novgorod, 603950, Russia \\ E-mail: mikhail.ivashkin@gmail.com
}

\begin{abstract}
The article is devoted to the analysis of relations of France with the states of the Middle East region through the prism of foreign policy of Nicolas Sarkozy and Francois Hollande. The Middle East direction of foreign policy is traditional for the Republic, and therefore it is included in the sphere of foreign policy priorities of the state leaders. The aim of this paper is to compare the Middle Eastern policy of France under the presidency of N. Sarkozy with the course of F. Hollande. In order to achieve this goal, a number of tasks must be accomplished, in particular: to examine the implementation of the foreign policy of the presidents in relation to the countries of the Middle East; to highlight the general trends in the Middle East policy of the two presidents; to analyze the differences between their Middle East policies. Ultimately, the author comes to the conclusion that the presidents' views in 2007-2014 are consistent, most traditional contacts are preserved and cooperation is expanded. The change lies in the
\end{abstract}


intensity of interaction. Thus, the personal qualities and beliefs of both politicians have strengthened some connections and caused the cooling of others, and caused a shift in some accents.

Keywords: France, Middle East, Nicolas Sarkozy, Francois Hollande, Libya, Syria, Iraq, United Arab Emirates, Saudi Arabia, foreign policy.

For citation: Ivashkin M.A. 2020. French middle eastern policy during the presidency of Nicolas Sarkozy and Francois Hollande. Via in tempore. History and political science, 47 (4): 912-920 (in Russian). DOI: 10.18413/2687-0967-2020-47-4-912-920.

\section{Введение}

Традиционно Ближний Восток входит в зону интересов Франции, которая активно отстаивает свои позиции и продвигает свое видение расстановки сил в этом регионе. Основными направлениями ближневосточной политики Франции считаются ливаносирийское и палестино-израильское, где Париж пытается сохранить ровные контакты со всеми сторонами конфликта, а с другой стороны, естественно задевает интересы участников, т. к. государства ближневосточного региона демонстрируют сложное сплетение взаимных обид, конкуренции и поддержки. Также Пятая Республика поддерживает стабильно хорошие связи с Саудовской Аравией как центральным региональным игроком.

Приход к власти социалиста Франсуа Олланда существенно не поменял ближневосточный курс страны, переставив акценты, например, в плане поворота к Саудовской Аравии, но при сохранении жесткой позиции в сирийском и иранском вопросах. Н. Саркози задал определенный темп своему последователю, который, несмотря на оппозиционное положение во внутриполитической сфере, вынужден оставаться активным внешнеполитическим деятелем, не позволяя Франции терять возвращенные в регионе позиции.

\section{Политическое измерение}

Внешнеполитические доктрины Н. Саркози и Ф. Олланда на ближневосточном направлении во многом продолжили опыт Ж. Ширака и более глубокие традиции сохранения особой внешнеполитической идентичности Франции, заложенной еще Шарлем де Голлем [Агаджанян, 2012].

В конце XX - начале XXI вв. ближневосточный регион становится местом столкновения интересов целого ряда стран. Начиная с президентства Ж. Ширака, Ближний Восток стал для Франции новым «традиционным» внешнеполитическим направлением в битве за право считаться одним из ключевых государств мира, что отражается в «Белых книгах по обороне и безопасности» от 2008 и 2013 гг. [Агаджанян, 2012].

Вышедшая в июне 2008 г. «Белая книга» Николя Саркози задала внешнеполитический вектор Франции в период его президентства. В ней учитывались традиционные интересы государства в зоне исторического влияния (Северная Африка, северо-западное и северо-восточное побережья Африканского континента), а также потребности военнополитического и энергетического характера на ближневосточном направлении, прежде всего, в зоне Персидского залива [Livre Blanc. Defense et securite nationale, 2008].

Таким образом, внешнеполитическая стратегия Н. Саркози основывалась на предшествующих разработках, но привнесла и новые геополитические приоритеты. Прежде всего, Париж отказался от политики сокращения военного бюджета. Было объявлено об увеличении личного состава армии и удвоении расходов на создание собственной системы оповещения об атаках баллистических ракет, спутников-шпионов и т. д. [Агаджанян, 2012].

В «Белой книге» Н. Саркози констатировалось наличие «арки нестабильности от Атлантики до Индийского океана», то есть региона, протянувшегося от Атлантики через Средиземноморье к Персидскому заливу, странам Африканского Рога и Южной Азии [Li- 
vre Blanc. Defense et securite nationale, 2008]. Франция приступила к оптимизации своей военно-политической инфраструктуры на Африканском континенте и созданию точек военного базирования в зоне Залива. Данная стратегия отразилась в открытии военной базы в Абу-Даби в мае 2009 г., ставшей первым постоянным пунктом военного присутствия Франции в зоне Персидского залива с комплексной функциональной нагрузкой [Агаджанян, 2012].

Победа Ф. Олланда на выборах 2012 г. обозначила возможный отказ Франции от концепции «Гиперактивной внешней политики» Н. Саркози. Однако «Белая книга» 2013 г. в целом повторяла концепцию политики, прописанную в документе от 2008 г., за исключением сокращения расходов на разведывательные войска (на $15 \%$ ) и тяжелое вооружение (на 8\%) [Livre Blanc. Defense et securite nationale, 2013]. При этом и в новом документе подтверждалась значимость Ближнего Востока во внешней политике страны.

В своей предвыборной программе Н. Саркози обещал закончить французское присутствие в Афганистане к концу 2013 г. Ф. Олланд также неоднократно выступал с критикой операции НАТО в Афганистане. Так, например, в апреле 2008 г. он подчеркивал, что итог семилетнего пребывания французских войск в Афганистане мрачен - это талибы, наркотики, смерти.

Программа Ф. Олланда включала пункт о выводе французского военного контингента из Афганистана уже к концу 2012 г., несмотря на экспертное мнение о невозможности менять ситуацию в регионе. После победы политик огласил условия вывода войск: в Кабуле должны были остаться небольшие группы технического характера, которым было поручено помочь сформировать самостоятельные афганские военные кадры [Hollande pour un retrait d'Afghanistan «au plus tard à la fin 2012», 2012]. Вывод войск завершился в середине декабря 2012 г. - т. е. на год раньше срока по плану Н. Саркози и на два года раньше, чем это планировал сделать НАТО [Зверева, 2012].

Другой общей темой предвыборной гонки 2012 г. и взглядов обоих президентов в целом стал турецкий вопрос. Мнение Н. Саркози насчет вступления Турции в Евросоюз было прежним: страна не может присоединиться к ЕС ввиду своей исторической и географической роли «моста» между двумя мирами и двумя континентами. Отношения с этой страной бывший глава Французской Республики ухудшил к концу срока: закон о наказании за непризнание геноцида армян стал пиком напряженности в двусторонних отношениях. 22 декабря 2011 г. Парламент Франции одобрил законопроект об ответственности за отрицание геноцида, а 23 января 2012 г. этот законопроект был принят и верхней палатой Сената. Документом предусматривалось уголовное наказание в виде лишения свободы сроком до одного года и штраф в 45 тысяч евро для тех, кто отрицает геноцид армян в Османской империи в 1915 г. ${ }^{80}$ Однако уже в феврале 2012 г. Конституционный Совет Франции объявил о нелегальности текста данного закона, противоречащего праву граждан на свободу слова. В ответ Н. Саркози обратился к Правительству с просьбой принять новый закон ${ }^{81}$. Факт принятия закона Сенатом Франции вызвал одобрение Армении и протест Турции, которая отозвала своего посла и намеревалась ввести экономические санкции против Франции.

Франсуа Олланд в целом поддерживал позицию предшественника. Несмотря на подчеркивание стратегической роли Стамбула в урегулировании сирийского конфликта и призывы к налаживанию двусторонних отношений, ухудшенных за время президентства Н. Саркози, он высказывался против принятия Турции в ЕС. Первая причина заключалась в недостаточном развитии демократии в этой стране, что является важным условием при-

${ }^{80}$ Сенат Франции принял законопроект о геноциде армян, МИД Армении отправил благодарственное письмо. 2012. URL: http://www.gazeta.ru/news/lastnews/2012/01/24/n_2177593.shtml (дата обращения: 30.03 .2020$)$.

${ }^{81}$ КС Франции отменил наказание за непризнание геноцида армян. 2012 . URL: http://top.rbc.ru/society/29/02/2012/639675.shtml (дата обращения: 13.04.2020). 
соединения к Евросоюзу. Нерешенный «Кипрский вопрос» также представлял барьер, мешающий Турции претендовать на включение в состав Союза.

Такой политический шаг Н. Саркози и солидарность Ф. Олланда, с одной стороны, легко объяснить предвыборной гонкой 2012 года: поддержка полумиллиона армян, проживающих на территории Франции, могла стать решающей в определении победителя выборов. С другой стороны, ухудшение отношений с Турцией повлекло бы потерю важного экономического партнера ${ }^{82}$.

Таким образом, вопрос о геноциде армян встретил политический консенсус среди французских политических кругов. Начатая Саркози законотворческая инициатива продолжилась и после победы Олланда, когда тот намеревался снова представить в Сенат проект закона об уголовном наказании за отрицание геноцида армян [Génocide arménien: Hollande s'engage à reprendre le dossier s'il est élu, 2012]. Тем не менее в январе 2014 г. состоялся первый за 22 года официальный визит главы Франции в Турцию [Панюжева, c. 71].

Если говорить о другом традиционном векторе французской политики, то следует подчеркнуть преемственность в отношениях с Израилем. Благодаря активному французскому участию Израиль заполучил ядерные технологии и построил ядерные реакторы [Зинченко, с. 32]. Отдельное внимание стоит уделить влиянию мощной еврейской диаспоры на французское правительство. Среди всех французских политических партий именно социалисты традиционно поддерживали наиболее тесные связи с Тель-Авивом [Золина, 2007; c. 34].

Преемственность политического курса наблюдается и в отношении урегулирования израильско-палестинского конфликта. В своей деятельности Ф. Олланд придерживался установок Саркози - безопасность самого Израиля обеспечена признанием сосуществования с Палестиной. Президенты прикладывали дипломатические усилия для налаживания диалога между сторонами конфликта, а также поддерживали Рамаллу в ее стремлении обрести статус наблюдателя в рамках $\mathrm{OOH}$, которое было удовлетворено 31 октября 2012 года ${ }^{83}$.

Еще одно важное направление ближневосточной политики Пятой Республики - отношения с Саудовской Аравией, отличающиеся доверием, прочностью, разносторонней направленностью, а также принципом взаимности и уважения. Франция была одной из первых стран, признавших молодое государство в 1926 г. [Золина, 2010; с. 23].

С 1996 г. двусторонние отношения развиваются в формате «стратегического партнерства», которое сводится не только к усилению существующего сотрудничества, поощрению встреч, контактов, но и поиску совместного видения ситуации в регионе и мире [Présentation et Historique, 2019].

Рассматривая Саудовскую Аравию как влиятельного актора региональной и международной политики, Франция считает необходимым привлекать страну к вопросам поддержания безопасности и стабильности. Поэтому стороны сотрудничают в вопросах обеспечения мира в регионе и его целостности; разрешения арабо-израильских противоречий и отстаивания права Палестины на существование в качестве суверенного государства; единства и независимости Ирака и Ливана; нераспространения ядерного оружия; верховенства принципов международного права [Présentation et Historique, 2019]. Поддержка Бейрута и совместное с Эр-Риядом финансирование Ливана стало важным вектором регионального курса Парижа еще при Н. Саркози, что активно продолжил Ф. Олланд после вступления на пост главы государства.

82 Франция сделала преступлением отрицание геноцида армян. 2011 URL: http://www.bbc.co.uk/russian/international/2011/12/111221_france_turkey_armenia.shtml (дата обращения: 25.04.2020).

${ }^{83}$ Резолюция Генеральной Ассамблеи ООН № 67/19. Статус Палестины в Организации Объединенных Наций. 2012. Режим доступа: https://undocs.org/ru/A/67/L.19 (дата обращения: 05.05.2020). 
В целом, несмотря на различие внутриполитических убеждений двух президентов, политика Парижа в отношении стран Ближнего и Среднего Востока отличалась преемственностью: это касается и предвыборных заявлений относительно Турции и вывода войск из Афганистана, принципиально жесткой позиции в отношении иранской ядерной программы, сотрудничества с Саудовской Аравией в вопросе укрепления мира и стабильности в регионе, в первую очередь, на ливанском и палестинском направлениях, а также традиционных франко-израильских связей.

\section{Экономическое и культурное измерение}

Огромный экономический потенциал ближневосточного региона, обширная программа развития и стратегия диверсификации партнерских связей представляли для Франции хорошие перспективы. Поэтому при президенте Н. Саркози Франция существенно увеличила свое экономическое присутствие в этих странах, в частности в Саудовской Аравии, Катаре, Объединенных Арабских Эмиратах, Израиле.

Можно выделить три направления развития экономических связей.

Во-первых, эти страны являются стратегически важными для французских предприятий благодаря своей стабильности, экономическому росту, значению некоторых государств в рамках Совета по сотрудничеству стран Персидского Залива, а также благоприятному климату для развития партнерства. Макроэкономические параметры находятся на хорошем уровне благодаря доходам от поставок топлива, продуманной ценовой политике и осторожному планированию в период мирового финансового кризиса.

Во-вторых, партнерство и подписание больших контрактов обусловлено историческими связями Франции с регионом. Такие традиционные отрасли, как энергетика, особенно атомная и возобновляемая (в частности, саудовские власти разработали план по строительству 16 АЭС стоимостью 70 млрд евро наряду с внедрением солнечной энергии), электрификация, опреснение воды, авиа, ж/д и подземный транспорт, телекоммуникации и электронная промышленность рисуют долгосрочные перспективы для французских компаний [Галстян, 2013]. В Израиле, например, на 2017 г. располагалось порядка 50 филиалов французских компаний, где работало 6000 человек [La France et Israel, 2019].

В-третьих, ближневосточные страны представляют выгодный рынок сбыта для французских малых и средних предприятий. Наличие выгодной экономической ситуации, характеризующейся диверсификацией экономики и быстрыми темпами роста (в Саудовской Аравии они составили 307 \% с 2002 г.), а также отличное качество французских товаров - все это говорит о возможности французского бизнеса выигрывать от такого сотрудничества [Relations économiques bilatérales et presence économique française en Arabie saoudite, 2019].

Вопросы обороны и военного сотрудничества Франции с Ближним Востоком вырабатываются посольствами. С 2011 гг. назначаются начальники миссии по сотрудничеству в сфере обороны со странами региона. Наиболее развито это направление с Саудовской Аравией, являющейся ключевым игроком в арабском мире. Входящие в миссию по сотрудничеству офицеры выступают советниками Вооруженных Сил Эр-Рияда наряду с французскими коллегами [La Mission de defense et mission de cooperation de defense, 2019]. Деятельность охватывает 3 направления: обмен опытом в сфере обороны, военное сотрудничество, совместные действия в сфере разоружения.

Усиление роли Франции достигается и за счёт развития культурного элемента, который включает искусство, образовательную деятельность и научное сотрудничество. Кроме того, культурная политика позволяет жителям арабских государств больше узнать о французском искусстве и культуре, образовании и преодолеть трудности в различиях менталитета, что особенно связано с вопросом миграции [La cooperation culturelle, universitaire et scientifique, 2019].

Культурная политика включает несколько направлений. 
Во-первых, это развитие системы начального и среднего образования. Система саудовского образования в период кризиса повернула некоторые школы в сторону французского бакалавриата, поэтому нередким явлением стал выбор французской системы обучения от школы и до университета. Обучение французскому языку активно продвигается и в Палестине, где специальная программа с бюджетом в 700000 евро способствовала принятию образовательных программ по изучению языка на базе школ и других учебных заведений в Вифлееме, Наплузе, Хевроне [La France et les Territoires palestiniens, 2019].

Во-вторых, это гуманитарное и социальное сотрудничество, которое включает улучшение системы управления, реформирование правосудия, защиту прав человека и защиту детей, беженцев, развитие социальных программ. Договор о сотрудничестве министерств Франции и Саудовской Аравии нацелен на обучение штата и развитие карьеры, в частности в рамках французской системы Национальной Школы Магистратуры. Помощь в деятельности по защите прав человека осуществляется Первой Ассоциацией по правам человека [La France et les Territoires palestiniens, 2019].

B-третьих, это СМИ и культура. Наряду с развитием системы по обучению французскому языку Париж поощряет реализацию политики франкофонии посредством открытия культурных и языковых центров. Так, Французская Республика поддерживает свое влияние и осуществляет поддержку союзников. Например, в 2010 г. был создан Фонд солидарности, нацеленный на сохранение и увеличение ценности культурного и исторического наследия Палестины [La France et les Territoires palestiniens, 2019].

Наконец, Франция наращивает научное сотрудничество, которое развивается в различных областях при поддержке посольств через подписание договоров между исследовательскими структурами государств. Например, между французскими le CNRS и l'IRD и саудовскими KACST и KAUST [La cooperation culturelle, universitaire et scientifique, 2019]. Сотрудничество с Израилем строится на базе совместной лаборатории INSERM в Ницце, Французского Института в Тель-Авиве и Института технологий Technion, а также центров и филиалов в Хайфе и Беэр-Шеве [La France et Israël, 2019].

Таким образом, наблюдается постоянный интерес Франции к Ближневосточному региону как экономически выгодному и перспективному. Наличие исторических и социально обусловленных связей, а также региональные контуры военно-политических взаимоотношений стран обеспечивают увеличение числа контрактов, что было заложено Н. Саркози и продолжено Ф. Олландом. В условиях кризиса и внутренней социальноэкономической напряженности Франция использует Ближний Восток для улучшения экономической ситуации. Ключевыми партнерами при Ф. Олланде были Саудовская Аравия (хотя при Н. Саркози приоритет отдавался Катару) и Израиль, с которыми развивалось экономическое партнерство в военной и энергетической сферах, образовательной, культурной и научной областях. Вместе с тем Париж жертвует немалые суммы на развитие культурных связей и упрочение своего влияния в регионе как сильной страны мирового масштаба, в первую очередь это включает поддержку Палестины и гуманитарную помощь беженцам.

\section{Выводы}

Внешняя политика страны с приходом к власти Ф. Олланда подверглась изменениям, в первую очередь учитывая отличия в характере и манере поведения президентасоциалиста. Образ резкого, порывистого и эмоционального Николя Саркози на Ближнем Востоке (жесткие действия в отношении иммигрантов и ограничение свободы самоидентификации мусульман, вмешательство в их традиционный уклад жизни) скорее мешал развитию двусторонних связей, а клубок межгосударственных противоречий и сложных взаимоотношений внутри самого Персидского региона не позволял Франции укрепиться в качестве надежного партнера. 
Политическая деятельность Н. Саркози на Ближнем Востоке, порой излишняя активность и агрессивность не всегда имели положительные результаты, хотя связи с определенными странами усилились. Акцент был сделан на экономическом аспекте взаимоотношений, подписании контрактов и осуществлении финансовой помощи как рычаге давления и влияния государства в регионе.

Более умеренный и спокойный, прагматичный и взвешенный Ф. Олланд создал приятный и обнадеживающий образ с точки зрения арабских лидеров [Зверева, с. 84]. Вместе с комплексным подходом к реализации политики на Ближнем Востоке это позволило новому президенту Франции добиться расположения здешних политических элит, установить дружественные личные контакты и усилить роль страны на фоне ослабления влияния США в данном регионе.

Военизированная составляющая французской политики начинается с открытия первой постоянной военной базы в ОАЭ в мае 2009 г., что можно рассматривать как претензию на французское лидерство. А возобновление участия в военной структуре НАТО в том же году говорит о расширении методов и инструментов потенциального влияния республики, желающей ослабить влияние США на Ближнем Востоке. В условиях начавшейся «Арабской весны» Париж сделал упор на занятии ведущей роли в военной интервенции в Ливию, что могло повысить статус страны в регионе. Тем не менее сирийскую проблему Н. Саркози стал решать дипломатическими методами, делая усилия по восстановлению двусторонних отношений, ухудшенных при Ж. Шираке.

В свою очередь, Ф. Олланд поменял подход к сирийскому вопросу, сделав его более жестким и принципиальным. Франция не только первой признала «Национальную сирийскую коалицию», но и способствовала организации международной конференции для сбора средств в помощь оппозиции. Кроме этого, Франция - единственная из Европы, безоговорочно поддержавшая инициативу США по нанесению военного удара по Сирии в ответ на террористические действия, химические атаки и бомбардировки мирного населения сирийскими властями.

Традиционными партнерами Франции на Ближнем Востоке выступают Израиль и Саудовская Аравия, с которыми страна также наращивает экономическое и культурное сотрудничество. Они поддерживают Францию в ее действиях в регионе, а порой и сами задают тон, как это происходит с иранским направлением. Особую озабоченность Париж проявляет по отношению к политически нестабильному Ливану и Палестинским территориям, оказывая политическую и финансовую помощь и защищая их интересы на международном уровне.

В экономическом плане Париж продолжает эффективное сотрудничество со странами региона в инфраструктурной, космической и авиационной, энергетической отраслях, в реализации проектов по опреснению воды и электрификации, поставкам оружия и техники. Культурное направление носит разносторонний характер и нацелено на укрепление лидерства в странах Ближнего Востока и снижение роли США.

Таким образом, ближневосточный курс внешней политики Франции в период 2007-2014 гг. характеризуется преемственностью взглядов, сохранением большинства традиционных контактов и расширением сотрудничества. Изменения касаются в большей степени интенсивности взаимодействия: опыт, личные качества и убеждения обоих политиков укрепили одни связи и вызвали охлаждение других, вызвали перестановку некоторых акцентов. 


\section{Список литературы}

1. Агаджанян М. 2012. Ближний Восток во внешней политике Франции: от Триумфальной арки к «арке нестабильности». URL: http://oko-planet.su/first/109566-blizhniy-vostok-vovneshney-politike-francii-ot-triumfalnoy-arki-k-arke-nestabilnosti.html (дата обращения: 01.05.2020).

2. Галстян А. 2013. Франция возвращается на Ближний Восток. URL: http://yerkramas.org/article/66486/franciya-vozvrashhaetsya-na-blizhnij-vostok (дата обращения: 30.04.2020).

3. Зверева Т.В. 2012. Итоги президентских выборов и внешняя политика Франции. Международная жизнь. 5: 75-90.

4. Зинченко А.В. 2004. Ядерная политика Франции во второй половине ХХ в. М., 519.

5. Золина Д.М. 2007. Особенности взаимоотношений между Францией и Израилем (вторая половина XX - начало XXI вв.). Нижегородский журнал международных исследований. Н. Новгород: ННГУ: 30-44.

6. Золина Д.М. 2010. Развитие ближневосточной политики Франции в 1948-2008 гг. Н. Новгород: ННГУ: 18-31.

7. Панюжева М.M. 2013. Франция: новый президент - новый внешнеполитический курс? Современная Европа. Институт Европы РАН. 3: 57-73.

8. Livre Blanc. Defense et securite nationale. 2008. La Documentation Française. - URL: http://www.ladocumentationfrancaise.fr/var/storage/rapports-publics/084000341/0000.pdf (дата обращения: 03.04.2020).

9. Livre Blanc. Defense et securite nationale. 2013.Présidence de la République française. URL: http://www.elysee.fr/assets/pdf/Livre-Blanc.pdf (дата обращения: 03.04.2020).

10. Hollande pour un retrait d'Afghanistan «au plus tard à la fin 2012». 2012. Le Monde. URL: http://www.lemonde.fr/election-presidentielle-2012/article/2012/01/20/hollande-pour-un-retrait-dafghanistan-au-plus-tard-a-la-fin-2012_1632466_1471069.html (дата обращения: 03.04.2020).

11. Génocide arménien: Hollande s'engage à reprendre le dossier s'ilestélu. 2012. Le Monde.URL: http://www.lemonde.fr/election-presidentielle-2012/article/2012/02/28/genocide-armeniendes-deputes-ump-saluent-la-decision-du-conseil-constitutionnel_1649524_1471069.html (дата обращения: 16.04.2020).

12. La cooperation culturelle, universitaire et scientifique. 2019. URL: http://www.ambafrancesa.org/La-cooperation-culturelle (дата обращения: 17.04.2020).

13. La Mission de défense et mission de coopération de defense. 2019. URL: http://www.ambafrance-sa.org/La-Mission-de-defense-et-mission (дата обращения: 17.04.2020).

14. La France et Israël. 2019. URL: http://www.diplomatie.gouv.fr/fr/dossiers-pays/israelterritoires-palestiniens/la-france-et-israel/ (дата обращения: 17.04.2020).

15. La France et les Territoires palestiniens. 2019. URL: http://www.diplomatie.gouv.fr/fr/dossiers-pays/israel-territoires-palestiniens/la-france-et-les-territoires/ (дата обращения: 19.04.2020).

16. Présentation et Historique. 2019. L'ambassade de France à Riyad. - URL: http://www.ambafrance-sa.org/Presentation-et-Historique,397 (дата обращения: 02.04.2020).

17. Relations économiques bilatérale set présence économique française en Arabies aoudite. 2019. L'ambassade de France à Riyad. - URL: http://www.ambafrance-sa.org/Relations-economiquesbilaterales (дата обращения: 21.04.2020).

\section{References}

1. Agadjanyan M. 2012. Blizhniy Vostok vo vneshney politike Frantsii: ot Triumfalnoy arki k «arke nestabilnosti» [The Middle East in French foreign policy: from the Arc de Triomphe to the «Arch of Instability»]. URL: http://oko-planet.su/first/109566-blizhniy-vostok-vo-vneshney-politike-francii-ottriumfalnoy-arki-k-arke-nestabilnosti.html (accessed: 01.05.2020).

2. Galstyan A. 2013. Frantsiya vozvrashchayetsya na Blizhniy Vostok [France returns to the Middle East]. URL: http://yerkramas.org/article/66486/franciya-vozvrashhaetsya-na-blizhnij-vostok (accessed: 30.04.2020).

3. Zvereva T.V. 2012. Itogi prezidentskikh vyborov i vneshnyaya politika Frantsii [Presidential election results and French foreign policy]. Mezhdunarodnaya zhizn.5: 75-90. 
4. Zinchenko A.V. 2004. Yadernaya politika Frantsii vo vtoroy polovine XX v. [France's nuclear policy in the second half of the twentieth century]. M., 519.

5. Zolina D.M. 2007. Osobennosti vzaimootnosheniy mezhdu Frantsiyey i Izrailem (vtoraya polovina XX - nachalo XXI vv.). Nizhegorodskiy zhurnal mezhdunarodnykh issledovaniy. N. Novgorod: NNGU: $30-44$.

6. Zolina D.M. 2010. Razvitiye blizhnevostochnoy politiki Frantsii v 1948-2008 gg. [The relationship between France and Israel (second half of the twentieth and beginning of the twenty-first centuries)]. N. Novgorod: NNGU, 18-31.

7. Panyuzheva M.M. 2013. Frantsiya: novyy prezident - novyy vneshnepoliticheskiy kurs? [France: new president - new foreign policy?]. Sovremennaya Evropa. Institut Evropy RAN. 3: 57-73.

8. Livre Blanc. Defense et securite nationale. 2008. La Documentation Française. - URL: http://www.ladocumentationfrancaise.fr/var/storage/rapports-publics/084000341/0000.pdf _ (дата обращения: 03.04.2020).

9. Livre Blanc. Defense et securite nationale. 2013.Présidence de la République française. URL: http://www.elysee.fr/assets/pdf/Livre-Blanc.pdf (дата обращения: 03.04.2020).

10. Hollande pour un retrait d'Afghanistan «au plus tard à la fin 2012». 2012. Le Monde. URL: http://www.lemonde.fr/election-presidentielle-2012/article/2012/01/20/hollande-pour-un-retrait-dafghanistan-au-plus-tard-a-la-fin-2012_1632466_1471069.html (дата обращения: 03.04.2020).

11. Génocide arménien: Hollande s'engage à reprendre le dossier s'ilestélu. 2012. Le Monde.URL: http://www.lemonde.fr/election-presidentielle-2012/article/2012/02/28/genocide-armeniendes-deputes-ump-saluent-la-decision-du-conseil-constitutionnel_1649524_1471069.html (дата обращения: 16.04.2020).

12. La cooperation culturelle, universitaire et scientifique. 2019. URL: http://www.ambafrancesa.org/La-cooperation-culturelle (дата обращения: 17.04.2020).

13. La Mission de défense et mission de coopération de defense. 2019. URL: http://www.ambafrance-sa.org/La-Mission-de-defense-et-mission (дата обращения: 17.04.2020).

14. La France et Israël. 2019. URL: http://www.diplomatie.gouv.fr/fr/dossiers-pays/israelterritoires-palestiniens/la-france-et-israel/ (дата обращения: 17.04.2020).

15. La France et les Territoires palestiniens. 2019. URL: http://www.diplomatie.gouv.fr/fr/dossiers-pays/israel-territoires-palestiniens/la-france-et-les-territoires/ (дата обращения: 19.04.2020).

16. Présentation et Historique. 2019. L'ambassade de France à Riyad. - URL: http://www.ambafrance-sa.org/Presentation-et-Historique,397 (дата обращения: 02.04.2020).

17. Relations économiques bilatérale set présence économique française en Arabies aoudite. 2019. L'ambassade de France à Riyad. - URL: http://www.ambafrance-sa.org/Relations-economiquesbilaterales (дата обращения: 21.04.2020).

\section{ИНФОРМАЦИЯ ОБ АВТОРЕ}

Ивашкин Михаил Александрович, аспирант Национального Нижегородского исследовательского государственного университета им. Н.И. Лобачевского, Института международных отношений и мировой истории, г. Нижний Новгород, Россия

\section{INFORMATION ABOUT THE AUTHOR}

Mikhail A. Ivashkin, postgraduate student, Institute of International Relations and World History, National Research Lobachevsky State University of Nizhny Novgorod, Nizhny Novgorod, Russia 